\title{
Intersecting Self-Efficacy and Interest: Exploring the Impact of Soft Robot Design Experiences on Engineering Perceptions
}

\section{Mr. Andrew Jackson, Purdue Polytechnic Institute}

Andrew Jackson is currently pursuing a PhD in Technology through Purdue's Polytechnic Institute, with an emphasis on Engineering and Technology Teacher Education. His research interests are engineering self-efficacy, motivation, and decision making. Andrew is the recipient of a 2015 Ross Fellowship from Purdue University and has been recognized as a 21st Century Fellow by the International Technology and Engineering Educators Association. He completed his Master of Science in Technology Leadership and Innovation at Purdue University with a thesis investigating middle school engineering self-efficacy beliefs. He previously taught middle school and undergraduate technology courses, accompanying both experiences with classroom research to improve practice.

\section{Prof. Nathan Mentzer, Purdue Polytechnic Institute}

Nathan Mentzer is an associate professor in the Purdue Polytechnic with a joint appointment in the College of Education at Purdue University. Hired as a part of the strategic P12 STEM initiative, he prepares Engineering/Technology candidates for teacher licensure. Dr. Mentzer's educational efforts in pedagogical content knowledge are guided by a research theme centered in student learning of engineering design thinking on the secondary level. Nathan was a former middle and high school technology educator in Montana prior to pursuing a doctoral degree. He was a National Center for Engineering and Technology Education (NCETE) Fellow at Utah State University while pursuing a Ph.D. in Curriculum and Instruction. After graduation he completed a one year appointment with the Center as a postdoctoral researcher.

\section{Prof. Rebecca Kramer-Bottiglio, Yale University}

Rebecca Kramer-Bottiglio is an Assistant Professor of Mechanical Engineering and Materials Science at Yale University. She completed her B.S. at the Johns Hopkins University, M.S. at U.C. Berkeley, and Ph.D. at Harvard University. Prior to joining the faculty at Yale, she was an Assistant Professor of Mechanical Engineering at Purdue University for four years. She currently serves as an Associate Editor of Frontiers in Robotics and AI: Soft Robotics, IEEE Robotics and Automation Letters, and IOPscience Multifunctional Materials. She is the recipient of the NSF CAREER Award, the NASA Early Career Faculty Award, the AFOSR Young Investigator Award, the ONR Young Investigator Award, and was named to Forbes' 201530 under 30 list. 


\title{
Intersecting Self-Efficacy and Interest: Exploring the Impact of Soft Robot Design Experiences on Engineering Perceptions
}

\begin{abstract}
This evidence-based practice paper analyzes student engineering self-efficacy and interest following a $9^{\text {th }}$-grade curriculum intervention which introduced soft robot design to the classroom. Achievement motivation theories often hold that the intersection of self-efficacy and task interest are predictive of choices and behavior. By leveraging domain-specific measurements for self-efficacy and interest, we focus on engineering self-efficacy and engineering career interest to inform the development of the curriculum experience. First, an overview of the curriculum highlights elements which theoretically support self-efficacy or career interest. Next, participating students' trajectories for self-efficacy and interest are mapped to investigate potential growth following the lessons. Most students did not change their level of interest or self-efficacy after the lessons, and we observed mixed results among those that did: some students increased and a similar number decreased in engineering perceptions. We examine the number of students with changing self-efficacy and interest and draw conclusions about curriculum revisions.
\end{abstract}

\section{Introduction}

According to the National Center for Science and Engineering Statistics (NCSES), women remain underrepresented in the science and engineering workforce [1], despite the breadth of attention STEM demographics have received in the past several decades. Furthermore, females working in the STEM disciplines are largely concentrated towards the social sciences and biological/medical sciences, where women currently make up 53\% and 51\% of the workforce, respectively. However, only $26 \%$ of computer scientists and mathematicians are female, and women represent only a staggering $13 \%$ of engineers in our American workforce [1].

While this problem is not new, it is certainly persistent. As such, it comes with an impressive collection of research and literature all seeking to answer the question, "Why aren't girls interested in STEM?". The perplexing finding is that they are. In a recent study on Women in STEM [2], researchers found that in the United States, two-thirds of young children (males and females alike) said they like science. However, the numbers began to drop-off in middle school and became increasingly divergent in high school. In another study, it was found that throughout high school years the percentage of females interested in a STEM career declined from an already low $15.7 \%$ (as high school freshman) to $12.7 \%$ (as seniors). Meanwhile, male interest in STEM careers remained stable, changing by only $0.2 \%$ over the duration of high school [3].

The question now shifts from "Why aren't girls interested in STEM?" to "Why aren't girls staying interested in STEM?". Studies addressing this query have been conducted, many of which centralize around hypotheses related to societal norms and the desire for girls to pursue "feminine" professions (including negative parental attitudes, stereotype threat, "chilly" classroom climate, and masculine pedagogy) [4, 5], self-concept and self-efficacy [6-8], and lack 
of exposure to female STEM role-models $[9,10]$ (although, this is a controversial point, as Cheryan, et al. [11] showed that role model gender has no effect on success beliefs).

Achievement motivation theories relate these psychological factors to students' choice and behavior. For example, Expectancy-Value Theory relates cultural, personal, and goal beliefs to expectations for success and task value to predict choice [12]. Similarly, Social Cognitive Theory relates personal factors, behavioral factors, and environmental aspects (i.e., self-efficacy beliefs, positive outcomes, and learning supports, respectively) to predict behavior. The application of these theories to career choices is evident: by understanding the psychological factors which promote choice and behavior we may be able to help students make choices that are congruent with their beliefs and interests, as well as overcome barriers to their career aspirations [13]. An important pattern among theories is the coupling of self-efficacy and interest for predicting choice - this means that neither alone are sufficient to fully understand career decision-making $[14,15]$.

Evidence demonstrates that the influence of self-efficacy and interest are maintained in engineering career decision-making. Lent, et al. [16] evaluated the choice of students' major and found self-efficacy and interest to be significant predictors-regardless of student gender or whether the student was attending a predominantly White or a historically Black college or university. Carrico and Tendhar [17] also reported evidence of a significant correlation between students' self-efficacy, interest, and goals to pursue engineering. While these two studies use different variables to approximate students' choice, the predictive utility of self-efficacy and interest is strengthened when the variables are used together.

Using this lens of parallel measures, this paper analyzes the content and year one implementation results of a $9^{\text {th }}$-grade design curriculum intended to grow students' self-efficacy, interest, and career choice for engineering. Following our research team's year-long curriculum development process, we have now been involved in the implementation process of soft robot design lessons as they are used by teachers (described in the next section). Using text from scales of engineering self-efficacy and interest, we reflect on the pedagogical strategies for enhancing student confidence and interest which emerge from the lesson content. Then, as a second method for evaluating the impact of our lessons, we map changes in student self-efficacy and interest scores reported before and after the soft robotics lessons. According to Wickham and Grolemund [18], these exploratory approaches offer insight that is not otherwise obtained. Along with more structured statistical analysis which we have reported elsewhere, the content analysis and characterization of changes in student perceptions support the refinement of the curriculum moving forward.

\section{Soft Robotics Design Experience}

This research effort was situated in a $9^{\text {th }}$ grade Engineering byDesign course in collaboration with the International Technology and Engineering Educators Association's STEM Center for Teaching and Learning. The STEM Center for Teaching and Learning ${ }^{\mathrm{TM}}$ has developed a standards-based national model for Grades K-12 that delivers technological literacy in a STEM context. The $9^{\text {th }}$ grade course is called Foundations of Technology and prepares students to understand and apply technological concepts and processes that are the cornerstone for the high school technology program. For students in the district where this research was conducted, it is a required course; this was intentional in our research design, capturing a variety of student 
interests, not just those who elect to take the course. Group and individual activities engage students in creating ideas, developing innovations, and engineering practical solutions. One of the units focuses on design documentation in the context of a robotics problem. Based on the nature of the existing two-week lesson, we developed an alternative lesson matching the objectives of the existing lesson but changing the context and materials to a soft pneumatically inflatable gripper.

In the soft robot design lesson, students work through the Engineering byDesign design process which includes 12 states from problem definition to communicating results. Students begin the lesson with a small activity where they think about the importance of documenting the design in an engineering design journal and then they format a design journal for their work with their teacher's guidance. Next, they are presented with a design problem (see Figure 1).

As an introduction to the necessary underlying principles, the teacher discusses fluid dynamics and pressure in contained vessels and transitions to pneumatic actuation. Modulus of Elasticity is introduced in the context of air pressure as different materials stretch when inflated differently. When introducing the design brief, the context of trying to pick up tomatoes (the design challenge) is simulated by picking up a golf ball. The teacher then leads a conversation about characteristics of a gripper that would be able to pick up a tomato. After that conversation, the teacher transitions to think about how to design for those characteristics. As part of the research study, teachers were provided kits for soft robotic fabrication, which can be arranged in a variety of configurations with different motion $[19,20]$. However, based on the materials available, some of the design ideas may not be feasible. Subsequently, the teacher leads a discussion about materials and processes, balancing between creativity and feasibility. Following a demonstration of how to safely work with silicone rubber and the mold kits, students work in pairs on the design project. They are encouraged to learn through two main channels: 1) via research on the internet (sites such as WwW.softroboticstoolkit.com) and 2) via hands-on prototyping and

Design Problem: Worldwide there are more people eating and fewer people producing food; we need to be more efficient and not damage what we have. You have been hired to design a robotic gripper to help a small farm operation be more efficient in picking up fragile produce. They have several different crops but their main yield is tomatoes about the size of a golf ball. Your gripper needs to help a farm worker accurately pick up the crop and sort it, all without damaging the food. Gripper should pick up, hold and release the tomatoes (golf balls). You should also be prepared to give training on your gripper and explain your design decisions (why you made it the way you did). Document your work using your electronic Engineering Design Journal.

\section{Specifications}

1. The robot gripper must be able to pick up a golf ball by inflating with the squeeze bulb pump.

2. The gripper must be able to securely hold the golf ball for 5 seconds.

3. The gripper must be able to release the golf ball by opening the air valve.

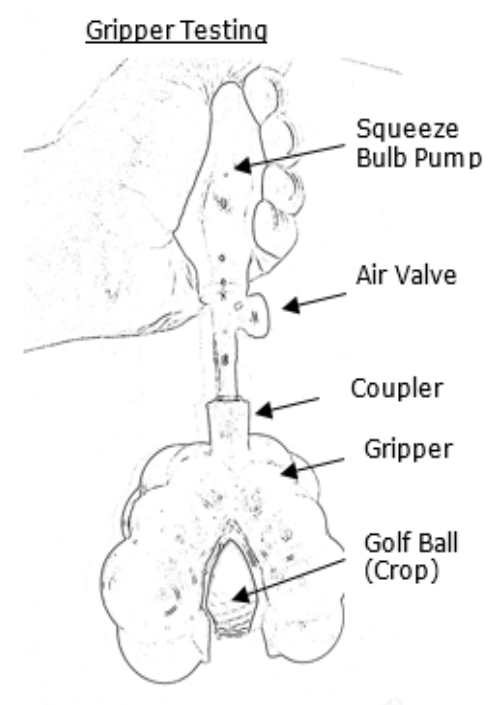

Figure 1. Design brief for soft robot design curriculum including gripper demonstration sketch. 
empirical testing done by building a small part of the gripper-just one gripper finger instead of the complete gripper. These process help students discover design variables and process variables [21]. The design process proceeds as students reflect on design and process decisions made and how these choices subsequently impacted the performance of their soft robot fingers. After two iterations of finger design and fabrication, students combine their literature findings and empirical discoveries in a decision matrix to evaluate the best design for their gripper. Students select an approach and design, fabricate their gripper, and test their gripper. The culminating experience in the lesson is to present their work to the class reflecting on the design experience through their documentation.

\section{Using Parallel Measures in Engineering Design}

Aspects of the lesson were intended to support perceptions of self-efficacy and interest, which are described next, and ultimately STEM career interest - all outcomes of focus for the research project. An organizer offered by Betz [22] further clarified the career-related outcomes which follow self-efficacy and interest perceptions:

Regardless of the specific measures utilized, [joint use of self-efficacy and interest] may be based on a cross-classification of interest and confidence, with each cell of the crosstabulation having unique implications for career exploration. (p. 231)

Figure 2 shows a simple matrix produced by classifying self-efficacy (confidence) and interest as high or low. Areas with high efficacy and interest present a strong possible area for career exploration. Areas of low efficacy and high interest suggest interventions to strengthen confidence. Comparably, areas of high efficacy and low interest suggest changes to enhance student perceptions of relevance and value of the domain. Finally, areas of low efficacy and low interest suggest a low priority area for student career exploration.

Simultaneous use of self-efficacy and interest measures can be used wherever there are parallel measures on the same domain [22]. Career interest inventories covering broad categories exist. However, measures of specific career behaviors may also offer insight into student thinking: these measures cover homogeneous types of activity and are targeted to the domain of interest $[23,24]$. Nonetheless, the accuracy of scale interpretations in parallel application such as this remains based upon whether the measures are used as intended, with the intended population and interpretation of scores [25].

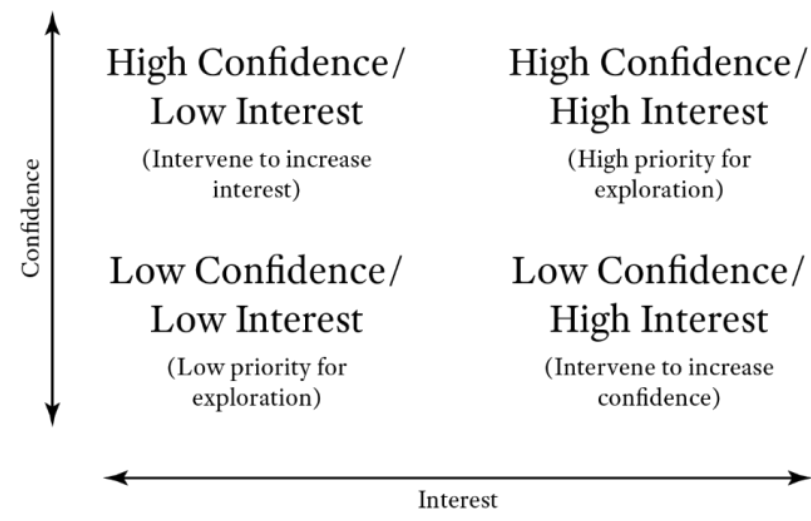

Figure 2. Quadrant display for confidence and interest cross-tabulation based on Betz. [22]. 


\section{Measures}

In order to gauge the efficacy of our curriculum intervention, three engineering-related scales were chosen, which cover student perceptions of self-efficacy and interest. First, to measure selfefficacy we used the General Engineering Self-Efficacy and Engineering Skills Self-Efficacy Scales [26] in combination. Next, for engineering interest we used the Engineering subscale of the STEM Career Interest Survey [27]. The development, content, and recommended use of the scales are described in turn.

The General Engineering Self-Efficacy Scale and Engineering Skills Self-Efficacy Scale were reported by Mamaril, et al. [26], though earlier dissertation work [28] provided the foundation for the later citation. The scales were intended to fill a gap in existing instruments, in that they followed self-efficacy scale development recommendations [such as 24] and balanced broad and task-specific perceptions of engineering self-efficacy. Seven hundred twenty-eight undergraduate students completed the surveys through their development process, leading to the final five and 12 item scales. Scores on the final instrument corresponded significantly to student motivation and academic outcomes in engineering. Follow-up validity analysis by Jackson [29], conducted with 317 high-school engineering students, emulated the original findings for the instrument. A minor difference indicated that questions on mastering engineering coursework were correlated, though the self-efficacy outcomes were still related to engineering motivation and persistence.

Among general engineering self-efficacy items are confidence to "...master the content in the engineering-related courses I am taking this semester" and "...do a good job on almost all my engineering coursework." The skill-specific items cover the engineering requisites of experimentation, tinkering, and design. These include, as examples, confidence to "... analyze data resulting from experiments," "...work with machines," and "...recognize changes needed for a design solution to work." All items are answered rating certainty to perform the task from 1 (completely uncertain) to 6 (completely certain). The content and theoretical structure of the scales suggest they are appropriate for use with high-school students.

The Engineering Subscale of the STEM-CIS [27] was used to measure student career interest. Each subscale of the STEM-CIS is based upon Social Cognitive Career Theory (SCCT) which offers a structure whereby personal inputs, environmental factors, and learning experiences lead to self-efficacy, outcome expectations, and eventually goals and actions. SCCT demonstrates the shared utility of self-efficacy and interest described previously, and is widely used in career counseling and research. Scale development was based upon responses from over 1,000 middle school students. Items from the Engineering Subscale include "I will work hard on activities at school that involve engineering," "My parents would like it if I choose an engineering career," and "I like activities that involve engineering"- the items cover a range of interest sources from personal to social. Each item was answered on a 5-point Likert scale for agreement from 1 (strongly disagree) to 5 (strongly agree). Kier, et al. [27] noted that based on the overall model fit and the fit indices for each subscale, it is appropriate to use the scales collectively or individually. Specifically, the Engineering Subscale demonstrated high reliability and unidimentionality (based on congeneric factor loadings). 


\section{Supporting Self-Efficacy and Interest}

Aspects of the lessons were intended to support these student perceptions since theories of selfefficacy and interest offer insight into curriculum design. While not a complete list, we describe the following pedagogical features of the design lessons (some unique to soft robot design) and note what self-perception they are designed to affect. It is also important to note that the lessons may emerge differently in practice, based on the professional judgment of the teacher.

- Iterative cycles of fabrication (self-efficacy): The curriculum is designed so that students start with a subcomponent of their final design, and have multiple opportunities to iterate, test, and refine the work before proceeding. The scale-up of this design work can support students' growing confidence as they have multiple successes, or learn from their ideas and eventually succeed [30]. The soft robot materials are unique in their requirement to fabricate a new design for each iteration (instead of tinkering with a previous version), encouraging students to think of new ideas.

- Accessible fabrication materials (self-efficacy): A hypothesis of the larger study for soft robot design is that by changing materials for robot construction, we can dispel the gender-based stereotypes that accompany traditional construction materials [32]. This may serve to "level the playing field" among boys and girls with regard to robot construction.

- Novel materials for fabrication (interest): The new fabrication materials are inherently surprising and novel. The actuation of soft materials can be non-linear and may pique curiosity among students.

- Human interfacing context and design challenge (interest): The design brief and example materials in the curriculum focus on solving a human need. While this is the intent of all design [33], the field of soft robotics has particular advantages for societal application due to built-in safety [34] and biological inspiration [35].

- Design freedom (interest): The curriculum follows the design process, which is divergent. Research, testing, and rationales can vary widely between student teams. While the fabrication materials pose some constraints, the mold materials have been designed and tested to be flexible and modular (author citation), meaning students have the ability to quickly experiment with a variety of designs.

- Information sharing among the class (self-efficacy): The curriculum is intended to include several opportunities for debrief after fabrication attempts. These are chances for the teacher and students to share what they are learning, and identify pitfalls so that others can be successful. The cooperative environment may provide models for successful behavior, a source of self-efficacy [31].

- Teamwork (self-efficacy): Students work in pairs to solve the design problem. This also presents opportunities for cooperation and peer models.

\section{Mapping Student Self-Efficacy and Interest}

The next phase of analysis - quantitative - complements the content analysis of the soft robotics lessons by using descriptive statistics and data visualization to describe changes in student perceptions. Based on students' self-reported survey data, two main questions asked were: 
1) What are the distributions of students' self-efficacy and interest scores before the lessons? and

2) How do these distributions change following the lessons?

To this end, survey data from 194 students was aggregated for students who had completed both measures (pre and post) while participating in the soft robotics lessons. The required nature of the course (in the district where this research was conducted) means that the gender balance of students in the course was roughly even; this was also the case for participating students. Descriptive statistics are reported. Next, scores were standardized so that the parallel measures would fall on the same scale. We address several questions by discretizing the self-efficacy and interest values to be high or low categories. Finally, we investigate student trajectories numerically and visually.

\section{Descriptive Statistics of Self-Efficacy and Interest Scores}

The current 194 students' responses were selected from among 441 student responses in a larger study which included a control group. Responses were removed if they were missing more than one question on either instrument at either time it was taken - in other words, to be included in the analysis of student trajectories we needed to know their starting point and ending point. The change between pre- and post-survey results was also used to discover outliers: Once the change scores were standardized, seven students were removed as outliers based on improbable values, $p<.001[36]$.

Descriptive statistics reported in Table 1 include the mean, median, standard deviation, skewness, and omega reliability [using 37]. Similar values between the mean and median, as well as the near-zero values for skewness, indicate that the distributions are approximately normal. The scores are also expected to be consistent for individuals, based on the high reliability of each scale [38]. Finally, when disaggregated by time, the self-efficacy and interest results have minor increase in means, yet remain reliable.

\section{Cross-Classification of Student Responses}

In completing the quadrant organization from Betz [22], the mean value at the pre-test was used as a divisor for low- and high-groups of self-efficacy and interest. The distributions were approximately normal; therefore, the mean is an appropriate measure of center. The first timepoint was used since it indicated a benchmark for student perceptions. It is important that this dividing value was applied to both pre- and post-survey data so that there existed a potential for all students to increase in self-efficacy and interest. If the post-test values had been divided on a different measure it would amount to moving target. We also recognize that this characterization is based on our external evaluation of reported self-efficacy and interest, which may be different than how students would describe their beliefs. 
Table 1. Descriptive statistics for self-efficacy and interest self-reports separated by time.

\begin{tabular}{|c|c|c|c|c|c|}
\hline Variable & $M$ & $M d n$ & $S D$ & Skewness & $\begin{array}{c}\omega \\
\text { Reliability }\end{array}$ \\
\hline \multicolumn{6}{|c|}{ Overall $(n=388)$} \\
\hline Self-Efficacy Total & 4.148 & 4.176 & 0.984 & -0.382 & 0.856 \\
\hline General Engineering & 4.069 & 4.200 & 1.143 & -0.486 & 0.867 \\
\hline Engineering Skills & 4.180 & 4.216 & 1.011 & -0.326 & 0.928 \\
\hline Interest & 3.164 & 3.182 & 0.824 & -0.119 & 0.795 \\
\hline \multicolumn{6}{|c|}{ Pre-Test $(n=194)$} \\
\hline Self-Efficacy Total & 4.102 & 4.176 & 0.968 & -0.472 & 0.830 \\
\hline General Engineering & 4.009 & 4.200 & 1.126 & -0.504 & 0.856 \\
\hline Engineering Skills & 4.140 & 4.167 & 1.007 & -0.374 & 0.906 \\
\hline Interest & 3.151 & 3.182 & 0.804 & -0.132 & 0.767 \\
\hline \multicolumn{6}{|c|}{ Post-Test $(n=194)$} \\
\hline Self-Efficacy Total & 4.193 & 4.235 & 1.000 & -0.308 & 0.879 \\
\hline General Engineering & 4.128 & 4.200 & 1.159 & -0.477 & 0.877 \\
\hline Engineering Skills & 4.220 & 4.292 & 1.016 & -0.281 & 0.944 \\
\hline Interest & 3.177 & 3.182 & 0.845 & -0.111 & 0.813 \\
\hline
\end{tabular}

Note: Self-Efficacy scores are on 6-point scale; Interest score is on 5-point scale.

Figure 3 shows the results for cross-classification of student self-efficacy and interest scores by time. Most students reported either high self-efficacy, high interest, or both, with only $29.4 \%$ of students beginning in the low-low category. Interest was the greater limitation in the beginning of the experience, with more students having lower interest than self-efficacy, however the proportion was roughly even. Comparing the proportion of students by time, after the experience more students held mixed perceptions. By gender there are also mixed results. Girls' interest grew slightly and self-efficacy decreased slightly, yet boys' interest decreased and self-efficacy grew- the opposite on both variables. We can uncover greater insight into changes in student perception by looking at the trajectory of each student than we can by the categorization totals alone.

Most students (64.43\%) did not change their classification for self-efficacy and interest after the curriculum (Table 2). However, the self-efficacy and interest perceptions of girls was more variable than that of boys - $41.82 \%$ of girls changed quadrants while only $27.38 \%$ of boys did. Only two students had mixed changes, one variable increasing and one decreasing, after the curriculum. Both students were female and both increased in interest yet decreased in selfefficacy. Among students changing perceptions overall, more students increased in self-efficacy than decreased (23 compared to 22 ) and the more students decreased in Interest than increased (15 increasing to 17 decreasing). 

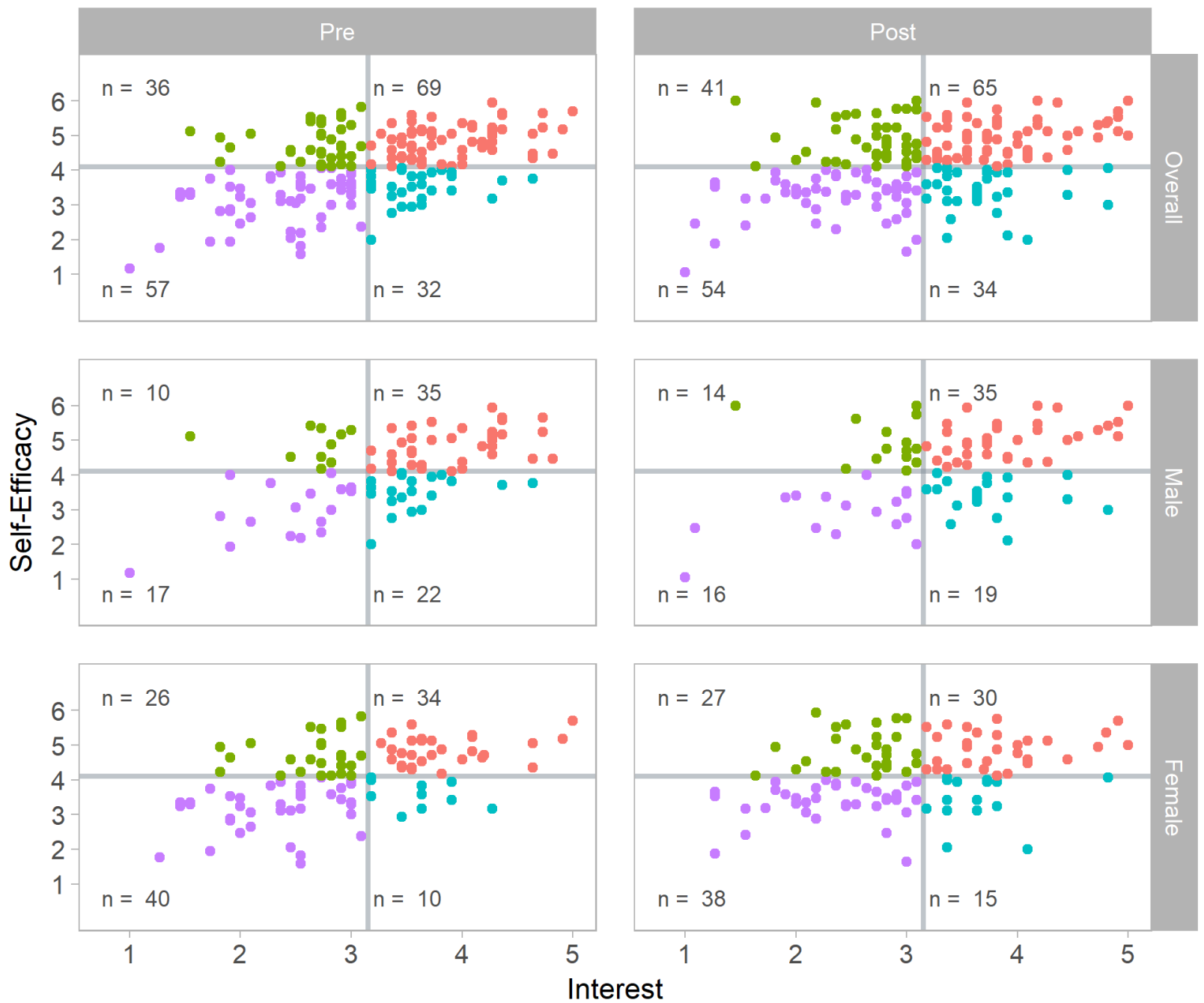

- High - High - High - Low - Low - High - Low - Low

Figure 3. Cross-Classification of self-efficacy and interest by time and gender. Self-efficacy and interest scores were classified as high or low based on the Pre-Test mean reported in Table 1 (marked in the scatterplots). The self-reported results are separated by time (left and right) and gender, with the overall results in the first row.

\section{Discussion}

The findings of student perceptions in our $9^{\text {th }}$ grade intervention are framed within the existing social biases and shortage of students interested, especially for girls. Approaches to increase selfefficacy and interest might be leveraged to grow students' career interests. Therefore, the present status and impact of engineering lessons on student perceptions are of interest. As designed, the curriculum had several anticipated supports for self-efficacy and interest.

As we analyze student survey results and the cross-classification of self-efficacy and interest, there are mixed findings. Interest was somewhat weaker for students at the beginning of the 
Table 2. Count and proportion of students changing on self-efficacy and interest outcomes.

\begin{tabular}{|c|c|c|c|c|c|c|}
\hline \multirow[b]{2}{*}{ Variable } & \multicolumn{2}{|c|}{ Overall } & \multicolumn{2}{|c|}{ Male } & \multicolumn{2}{|c|}{ Female } \\
\hline & Increase & Decrease & Increase & Decrease & Increase & Decrease \\
\hline $\begin{array}{l}\text { Self-Efficacy } \\
\text { and Interest }\end{array}$ & $5(2.58 \%)$ & $1(0.52 \%)$ & $2(2.38 \%)$ & - & $3(2.73 \%)$ & $1(0.91 \%)$ \\
\hline $\begin{array}{l}\text { Self-Efficacy } \\
\text { Only }\end{array}$ & $18(9.28 \%)$ & $19(9.79 \%)$ & $6(7.14 \%)$ & $4(4.76 \%)$ & $12(10.91 \%)$ & $15(13.64 \%)$ \\
\hline Interest Only & $8(4.12 \%)$ & $16(8.25 \%)$ & $3(3.57 \%)$ & $8(9.52 \%)$ & $5(4.55 \%)$ & $8(7.27 \%)$ \\
\hline Mixed+- & \multicolumn{2}{|c|}{$2(1.03 \%)$} & & \multicolumn{2}{|c|}{$2(1.82 \%)$} \\
\hline None & \multicolumn{2}{|c|}{$125(64.43 \%)$} & \multicolumn{2}{|c|}{$61(72.62 \%)$} & \multicolumn{2}{|c|}{$64(58.18 \%)$} \\
\hline
\end{tabular}

Note: Entries show number and percentage of total by gender (overall, male, or female). Unless indicated the responses fell within the same quadrant on the pre-test and post-test.

experience, though self-efficacy and interest had nearly equivalent numbers of low- and highperception students. Despite many students reporting changes on the scales over time, the scale means were nearly equivalent before and after the lessons. This is explained by the observation that students increasing in self-efficacy or interest were met by a similar number with negative changes in their perceptions, which remained true for boys and girls.

While the curriculum experience did not demonstrate findings for consistently promoting selfefficacy and interest, the variability among student responses when comparing before and after the lessons is promising for future teaching approaches. Over $40 \%$ of girls changed in their cross-classification of self-efficacy or interest. This contributes to the fields' current understanding on the nature of student perceptions, and offers evidence to suggest these beliefs are still malleable in high-school.

What might explain the changes in student scores or the inconsistency in those changes? A decision of this work was to use the exploratory cross-classification framework, rather than attempting statistical testing. This is more appropriate given that we have only reported on students who were in the new soft robot lessons. And statistical analysis of the broader set of student responses, reported elsewhere, did not identify meaningful differences [39]. Yet, in the exploratory approach taken here, we solely examined self-efficacy and interest, and did not account for teacher attributes, let alone outside student attributes. The research study involved seven teachers and more than 20 course sections, which presented differing environmental and educational features. It is possible that teacher- or classroom-level effects would explain further variation in students' scores. Students' self-efficacy and interest beliefs are also situated among a milieu of other factors, which may be used to explain why, and the directionality, of some students' changes in self-efficacy and interest. Further work could focus on these student characteristics quantitatively_-by regressing differences in student scores on other characteristics or attitudes — or qualitatively — by better uncovering the details and uniqueness of students' experiences.

How can the curriculum be changed to increase students' self-efficacy and interest? Whatever the level of these two student perceptions, further attempts to improve the curriculum would be undertaken. Towards a hopeful increase in self-efficacy and interest, we have modified and 
emphasized features of the curriculum and teacher preparation. For example, we have reframed the iterative cycle of fabrication (making fingers before a complete gripper) as a research opportunity to inform the final design. While this may be apparent as educators, the language shift from prototyping to research may further emphasize learning, and the acceptability of failure, to novice designers, thereby increasing students' confidence in spite of failure [40]. The context has also been modified to be more human-centric, focusing on medical applications of the gripper design. This approach may be useful for increasing interest, especially among girls, who tend to value careers with societal benefit [41]. Beyond these two primary changes, general refinements to the fabrication instructions, design process guidelines, and teacher professional development experience may trickle down to impact student self-efficacy and interest. Fortunately, our research is ongoing with the results of these implementation changes remaining to be seen.

\section{Acknowledgment}

This material was supported by the National Science Foundation under Grant DRL-1513175.

\section{References}

[1] National Science Board, "Science and engineering indicators digest 2012," Author, Arlington, VA,2012.

[2] K. D. Welde, S. Laursen, and H. Thiry, "Women in science, technology, engineering and math (STEM)," Sociologists for Women in Society, University of Kansas, Lawrence, KS,2007.

[3] P. M. Sadler, G. Sonnert, Z. Hazari, and R. Tai, "Stability and volatility of STEM career interest in high school: A gender study," Science Education, vol. 96, pp. 411-427, 2012.

[4] J. D. Stolk, "The impacts of societal context on student motivation and engagement," in MRS Online Proceedings Library, 2013.

[5] M. Wyer, "Intending to stay: Images of scientists, attitudes towards women, and gender as influences on persistence among science and engineering majors," Journal of Woman and Minorities in Science and Engineering, vol. 9, pp. 1-16, 2003.

[6] M. Beier and A. Rittmayer, "Literature overview: Motivational factors in STEM: Interest and self-concept," Rice University, Houston, TX,2008.

[7] M. A. Hutchison, D. K. Follman, M. Sumpter, and G. M. Bodner, "Factors influencing the self-efficacy beliefs of first-year engineering students," Journal of Engineering Education, vol. 95, pp. 39-47, 2006.

[8] R. M. Marra and B. Bogue, "Women engineering students' self efficacy -- a longitudinal multi-institution study," in Women in Engineering Programs \& Advocates Network, Pittsburgh, PA, 2006.

[9] L. S. Hirsch, S. Berliner-Heyman, R. Cano, H. Kimmel, and J. Carpinelli, "Middle school girls perceptions of engineers before and after a female only summer enrichment program.," in 2011 Frontiers in Education Conference, Rapid City, SD, 2011.

[10] D. M. Marx and J. S. Roman, "Female role models: Protecting women's math test performance," Personality and Social Psychology Bulletin, vol. 28, pp. 1183-1193, 2002. 
[11] S. Cheryan, J. O. Siy, M. Vichayapai, B. J. Drury, and S. Kim, "Do female and male role models who embody STEM stereotypes hinder women's anticipated success in STEM?," Social Psychological and Personality Science, vol. 2, pp. 656-664, 2011.

[12] A. Wigfield and J. S. Eccles, "The development of achievement task values: A theoretical analysis," Developmental Review, vol. 12, pp. 265-310, 1992.

[13] S. D. Brown and R. W. Lent, "Preparing adolescents to make career decisions: A social cognitive perspective," in Self-efficacy beliefs of adolescents, F. Pajares and T. C. Urdan, Eds., ed Greenwich, CT: Information Age Publishing, 2006, pp. 201-223.

[14] D. A. C. Donnay and F. H. Borgen, "The incremental validity of vocational self-efficacy: An examination of interest, self-efficacy, and occupation," Journal of Counseling Psychology, vol. 46, pp. 432-447, 1999.

[15] U. Trautwein, H. W. Marsh, B. Nagengast, O. Lüdtke, G. Nagy, and K. Jonkmann, "Probing for the multiplicative term in modern expectancy-value theory: A latent interaction modeling study," Journal of Educational Psychology, vol. 104, pp. 763-777, 2012.

[16] R. W. Lent, S. D. Brown, H.-B. Sheu, J. Schmidt, B. R. Brenner, C. S. Gloster, et al., "Social cognitive predictors of academic interests and goals in engineering: Utility for women and students at historically black universities," Journal of Counseling Psychology, vol. 52, pp. 84-92, 2005.

[17] C. Carrico and C. Tendhar, "The use of the social cognitive career theory to predict engineering students' motivation in the produced program," in 2012 ASEE Annual Conference \& Exposition, San Antonio, TX, 2012.

[18] H. Wickham and G. Grolemund. (2017). R for data science : Import, tidy, transform, visualize, and model data. Available: http://r4ds.had.co.nz/

[19] A. Jackson, N. Mentzer, R. Kramer, and J. Zhang, "Maker: Taking soft robotics from the laboratory to the classroom," in Make It! Event during the 2017 ASEE Annual Conference \& Exposition, Columbus, OH, 2017.

[20] A. Jackson, J. Zhang, R. Kramer, and N. Mentzer, "Design-based research and soft robotics to broaden the STEM pipeline (work in progress)," in 2017 ASEE Annual Conference \& Exposition, Columbus, OH, 2017.

[21] J. Zhang, A. Jackson, N. Mentzer, and R. Kramer, "A modular, reconfigurable mold for a K-12 soft robotic gripper design activity," Frontiers in Robotics and AI, vol. 4, pp. 1-8, 2017.

[22] N. E. Betz, "Developing and using parallel measures of career self-efficacy and interests with adolescents," in Self-efficacy beliefs of adolescents, F. Pajares and T. C. Urdan, Eds., ed Greenwich, CT: Information Age, 2006, pp. 225-244.

[23] A. Bandura, "Guide for constructing self-efficacy scales," in Self-efficacy beliefs of adolescents, F. Pajares and T. C. Urdan, Eds., ed Greenwich, CT: Information Age Publishing, 2006, pp. 307-337.

[24] M. Bong, "Asking the right question: How confident are you that you could successfully perform these tasks?," in Self-efficacy beliefs of adolescents, F. Pajares and T. C. Urdan, Eds., ed Greenwich, CT: Information Age Publishing, 2006, pp. 287-305.

[25] American Educational Research Association, American Psychological Association, and National Council on Measurement in Education, Standards for educational and psychological testing. Washington, DC: American Educational Research Association, 2014. 
[26] N. A. Mamaril, E. L. Usher, C. R. Li, D. R. Economy, and M. S. Kennedy, "Measuring undergraduate students' engineering self-efficacy: A validation study," Journal of Engineering Education, vol. 105, pp. 366-395, 2016.

[27] M. W. Kier, M. R. Blanchard, J. W. Osborne, and J. L. Albert, "The development of the STEM career interest survey (STEM-CIS)," Research in Science Education, vol. 44, pp. 461-481, 2013.

[28] N. J. A. Mamaril, "Measuring undergraduate students' engineering self-efficacy: A scale validation study," Doctoral Dissertation, Educational, School, and Counseling Psychology, University of Kentucky, Lexington, KY, 2014.

[29] A. Jackson, "Validity evidence for the general engineering self-efficacy and engineering skills self-efficacy scales with secondary students," in 2018 ASEE Illinois-Indiana Section Conference, West Lafayette, IN, 2018.

[30] T. Kelley and D. Kelley, Creative confidence: Unleashing the creative potential within us all. New York: Crown Business, 2013.

[31] A. Bandura, "Self-efficacy: Toward a unifying theory of behavioral change," Psychological Review, vol. 84, pp. 191-215, 1977.

[32] S. Hartmann, H. Wiesner, and A. Wiesner-Steiner, "Robotics and gender: The use of robotics for the empowerment of girls in the classroom," in Gender designs IT:

Construction and deconstruction of information society technology, I. Zorn, S. Maass, E. Rommes, C. Schirmer, and H. Schelhowe, Eds., ed Wiesbaden, Germany: VS Verlag für Sozialwissenschaften, 2007, pp. 175-188.

[33] International Technology Education Association, Standards for technological literacy: Content for the study of technology, 3rd ed. Reston, VA: Author, 2007.

[34] F. Ilievski, A. D. Mazzeo, R. F. Shepherd, X. Chen, and G. M. Whitesides, "Soft robotics for chemists," Angewandte Chemie, vol. 123, pp. 1930-1935, 2011.

[35] H. Lipson, "Challenges and opportunities for design, simulation, and fabrication of soft robots," Soft Robotics, vol. 1, pp. 21-27, 2014.

[36] B. G. Tabachnick and L. S. Fidell, Using multivariate statistics, 5th ed. Boston, MA: Pearson/Allyn \& Bacon, 2007.

[37] R. P. McDonald, "Test theory: A unified approach," ed: Mahwah, NJ: Lawrence Erlbaum, 1999.

[38] R. M. Thorndike and T. Thorndike-Christ, Measurement and evaluation in psychology and education, 8th ed. Boston, MA: Pearson, 2010.

[39] A. Jackson, N. Mentzer, and R. Kramer-Botiglio, Pilot analysis of the impacts of soft robotics design on high-school student engineering perceptions. Manuscript submitted for publication, 2018.

[40] P. S. Lottero-Perdue and E. A. Parry, "Elementary teachers' reflections on design failures and use of fail words after teaching engineering for two years," Journal of Pre-College Engineering Education Research, vol. 7, pp. 1-24, 2017.

[41] R. Su and J. Rounds, "All STEM fields are not created equal: People and things interests explain gender disparities across STEM fields," Front Psychol, vol. 6, p. 189, 2015. 